\title{
Nano-hardness, EBSD analysis and mechanical behavior of ultra-fine grain tungsten for fusion applications as plasma facing material
}

\author{
L Tanure ${ }^{a, b *}$, A Bakaeva ${ }^{c, d}$, L Lapeire ${ }^{a}$, D Terentyev , M Vilémováe, J Matějíček $^{\mathrm{e}}$ and K \\ Verbeken $^{\mathrm{a}}$ \\ ${ }^{a}$ Department of Materials, Textiles and Chemical Engineering, Ghent University (UGent), \\ Technologiepark 903, B-9052 Ghent, Belgium \\ ${ }^{b}$ Dutch Institute for Fundamental Energy Research, DIFFER, De Zaale 20, 5612 AJ \\ Eindhoven, The Netherlands \\ ${ }^{c}$ Nuclear Materials Science Institute, SCK.CEN, Boeretang 200, 2400 Mol, Belgium \\ ${ }^{d}$ Department of Applied Physics, Ghent University (UGent), St. Pietersnieuwstraat 41, 9000 \\ Ghent, Belgium \\ ${ }^{e}$ Institute of Plasma Physics, Za Slovankou 3, 18200 Prague, Czech Republic
}

\begin{abstract}
Tungsten and its alloys have been extensively studied in order to be used in plasma facing components for future fusion nuclear reactors such as ITER and DEMO. In this work, an evaluation of nano-hardness, microstructure/texture and mechanical behavior using nanoindentation, electron backscatter diffraction (EBSD) and tensile test was performed. The investigated materials were ultra-fine grain lab-scale tungsten and ITER-specification commercial tungsten products, taken as reference in the as-received and annealed (at $1300^{\circ} \mathrm{C}$ for 1 hour) conditions. Three ultra-fine grain (UFG) tungsten grades were produced under different spark plasma sintering conditions, namely at $2000^{\circ} \mathrm{C}$ and $70 \mathrm{MPa}$, at $1700^{\circ} \mathrm{C}$ and $80 \mathrm{MPa}$ and, finally, at $1800^{\circ} \mathrm{C}$ and $80 \mathrm{MPa}$. EBSD analysis provides very relevant data as it is known that the crystallographic orientation affects some features of the surface damage caused by fusion-relevant plasma exposure. The present results will serve as a reference for future studies that will be carried out using plasma-exposed samples in order to correlate the observed damage with the microstructural characteristics and mechanical behavior.
\end{abstract}

Keywords: Tungsten, EBSD, nano-hardness, microstructure, texture, mechanical behavior. 


\section{1-Introduction}

Tungsten and its alloys are the most promising materials to be used as plasma-facing components (PFCs) in future nuclear fusion reactors. Due to its high melting temperature $\left(3422^{\circ} \mathrm{C}\right)$, low solubility for hydrogen isotopes, low physical sputtering yield and high thermal conductivity, tungsten has being extensively studied in order to be used under fusion relevant loading conditions: high operational temperature, high particles flux and cyclic heating loads [1-4]. Despite such severe conditions, structural integrity needs to be guaranteed and the material should keep its properties as long as possible.

Because of its high melting temperature, manufacturing of tungsten is, very often, made through powder metallurgy. As traditional processing of powders, which involves pressing, sintering, and long holding times could lead to unwanted grain growth, alternative routes have been proposed. Spark Plasma Sintering (SPS) has the advantages of lower process temperature, increased heating rates and reduced holding times [5]. Importantly, the possibility of using nano-grain powder in the spark plasma sintering process may open a new perspective for the improvement of the material performance under plasma exposure and neutron irradiation. Recently, it has been demonstrated that initial microstructure (in terms of dislocation density and grain size) does play an important role with respect to uptake and release of plasma components as well as the modification of local mechanical properties of the surface (see e.g. [6-11]). Moreover, the reduction of the grain size should enhance the sink efficiency for neutron-induced irradiated defects, thereby potentially raising a positive effect with respect to accumulation of the irradiation-originated microstructure[12].

Thus, before evaluating the effects of the plasma exposure on specific properties of tungsten grades, it is important to thoroughly characterize unexposed samples in terms of both microstructure and mechanical properties. Microstructural features, such as the 
crystallographic orientation of the grains, have proven to be important when the material is exposed to high heat and particle fluxes (see e.g. [13]). Therefore, this information would finally help to design materials with a dedicated microstructure that could best fit technological conditions for applications in PFCs. The purpose of this work is to evaluate properties of tungsten materials produced by different processing routes using nano-hardness, EBSD and tensile test in un-exposed state. It will serve as a reference for later studies on plasma exposed samples produced via similar routes and tested with the same techniques. These materials are considered to be the most promising PFCs for ITER and DEMO fusion reactors.

\section{2-Experimental Procedure}

\section{1-Materials}

Two different processes were used to obtain the studied materials. Two samples were produced by Plansee SE (Reutte - Austria), in a bar (with square cross-section of $1296 \mathrm{~mm}^{2}$ ) which was fabricated by hammering of polycrystalline tungsten from both sides (specified purity of $99.97 \mathrm{wt} \%)$. These samples are: ITER specification products as-received (IG1000), that was stress relieved for 1 hour at $1000{ }^{\circ} \mathrm{C}$, and ITER-qualified annealed at $1300^{\circ} \mathrm{C}$ for 1 hour (IG1300), some preliminary study was made earlier $[14,15]$. The other three Ultra Fine Grain (UFG) samples starting from different tungsten powders (with a purity of $99.7 \mathrm{wt} \%$ ) were produced at Institute of Plasma Physics (IPP-Prague - Czech Republic) by Spark Plasma Sintering using $40 \mathrm{~g}$ of tungsten as round disks with a $30 \mathrm{~mm}$ diameter. A heating rate of $100^{\circ} \mathrm{C} / \mathrm{min}$ and a holding time of 2 minutes were applied and a final thickness of approximately $3.2 \mathrm{~mm}$ was reached, other conditions were: $1700^{\circ} \mathrm{C}$ and $80 \mathrm{MPa}$ in helium atmosphere (sample SPS1), $1800^{\circ} \mathrm{C}$ and $80 \mathrm{MPa}$ (sample SPS2) and, finally, $2000^{\circ} \mathrm{C}$ and 70MPa (sample SPS3). Both SPS2 and SPS3 were sintered in a combined argon and hydrogen atmosphere. The SPS1 had a maximum oxygen content of $0.30 \%$ and grain size of 
0.4-0.5 $\mu \mathrm{m}$. Whereas the SPS2 samples had a maximum oxygen content of $0.20 \%$ and a grain size of $0.6-0.7 \mu \mathrm{m}$ and, finally, sample SPS3 had a maximum oxygen content of $0.10 \%$ and a grain size ranging from 1.7 to $2.1 \mu \mathrm{m}$. These parameters are summarized in Table 1 .

\section{2-Sample preparation}

Samples with dimensions $10 \times 10 \times 0.8 \mathrm{~mm}^{3}$ were prepared according to the standard metallographic procedures of cutting, grinding and polishing. For EBSD analysis, samples were polished until $1 \mu \mathrm{m}$ diamond paste and then electro-polished using a $2 \% \mathrm{NaOH}$ solution, 15V for 12s. A Field Emission Gun Quanta-450 FEI Scanning Electron Microscope, with $20 \mathrm{kV}$ acceleration voltage, was used to scan each sample in two different fields: a field of $512 \times 512 \mu \mathrm{m}$ (step size $0.8 \mu \mathrm{m}$ ) and a field of $64 \times 64 \mu \mathrm{m}$ (step size $0.1 \mu \mathrm{m})$. During the image post-processing, with the aid of OIM ${ }^{\circledR}$ Analysis software, points with Confidence Index lower than 0.1 were removed. No other clean-ups were applied on the datasets. ITER-qualified samples were analyzed through longitudinal section in the middle of thickness while spark plasma sintered samples were evaluated through the axial section (section normal to the bar axis). All the measurements regarding texture, grain size, grain boundaries and Kernel Average Misorientation were made using the data obtained in the larger field $(512 \times 512 \mu \mathrm{m})$, while the Inverse Pole Figures were obtained from the smaller field $(64 x 64 \mu \mathrm{m})$.

Tensile tests were performed at $400^{\circ} \mathrm{C}$ and $600^{\circ} \mathrm{C}$ with deformation rate of $0.2 \mathrm{~mm} / \mathrm{min}$. Samples with elongated grains were cut with grains oriented parallel (longitudinal) and perpendicular (transversal) to the loading direction. The samples were cut by electric discharge machine (by W wire with a thickness of 20-100 $\mu \mathrm{m}$ ) and special surface treatment was applied further.

Agilent G200 nanoindenter was used to measure the Young's modulus and hardness. All measurements were performed in the continuous stiffness mode (CSM) with the standard XP 
head equipped with Berkovich diamond tip. The samples were indented up to a penetration depth $\mathrm{h}_{\mathrm{NI}}=1.5 \mu \mathrm{m}$ with the strain rate of $0.05 \mathrm{~s}^{-1}$.

\section{3-Results and Discussion}

\section{1-EBSD}

Figure 1 shows Inversed Pole Figure (IPF) maps for the ITER-qualified (hammered samples). For the IPFs the reference color system is related to the Bar Axis, BA, which means that blue color represents grains with $<111>$ parallel to BA, red represents grains with <001> parallel to BA and green represents grains with their $<101>$ parallel to BA.

As can be seen in the Figure 1 (a) and (b) the microstructures consist of elongated grains parallel to the bar axis. Both results are in accordance with microstructural features that can be expected for heavily deformed metals. It is possible to notice small, slightly elongated, sub-grains inside the grains. The elongated grains are mostly separated from each other by High-Angle Grain Boundaries (HAGBs), with a misorientation angle larger than $15^{\circ}$, while sub-grains are separated from each other by Low-Angle Grain Boundaries (LAGBs), with misorientation angle between $2^{\circ}$ and $15^{\circ}$.

For IG1000 the length of the grains ranges from $4-22 \mu \mathrm{m}$ and their width from 2-8 $\mu \mathrm{m}$, while for the annealed IG1300 these values are 4-16 $\mu \mathrm{m}$ and 2-10 $\mu \mathrm{m}$, respectively. These values were obtained using the linear intercept method in the horizontal (// BA) and vertical (//ND) direction. The annealing was responsible for shortening the elongated grains and a slight increase in their width. During the annealing, consequently, the density of LAGBs was reduced and the stored energy in the material is lowered [16].

As a next step, the texture was evaluated using classic Pole Figure representations and are shown in Figure 2. 
In Figure 2, similar texture components are observed for both conditions, yet a globally fairly random texture is observed. There is a slight strengthening in components <110> approximately parallel to the bar axis while also some changes in the 111 pole figure are observed with a decrease in the maximum component intensity comparing IG1000 to IG1300. A reduction in the maximum intensity upon annealing was also observed by Xia et al. in heavily deformed and annealed tungsten sheets and was associated with sub-grain coalescence which makes the annealing texture similar to the deformation texture, but with lower intensity levels [17]. On the other hand, Reiser et al. [18] investigated microstructural evolution in tungsten foils that were hot rolled, cold rolled and then annealed at different temperatures, and observed a strengthening of the deformed texture components in the annealed specimen after recrystallization. This difference in the behavior can be related to the variation in the kinetics of annealing that occur in thin foils and is not representative for the bulk [16]. Dislocations can easily move to the free surface of the thin foil (being driven by so-called called image forces) which alters the misorientation at LAGBs, while surface energy related features have demonstrated before to affect texture evolution [19]. In the case of bulk samples, the dislocations can annihilate/recombine with each other or become incorporated into the grain boundary interfaces, but do not escape to the free surface.

Grains with directions <111> // ND are prone to blister formation when exposed to high-flux deuterium plasma, while directions $<001>/ /$ ND are the most resistant ones $[13,20,21]$. This dependence on crystallographic orientation is very relevant for PFCs and it is also related to surface finish and hydrogen absorption and diffusion [22,23]. The present study indicates that annealing might worsen the texture and therefore make the material possibly more prone to blistering that should be seen as negative consequence of the operation because large blisters may also act as crack initiators. Annealing the samples at higher temperatures might provide an indication whether this trend persists upon sample recrystallization. 
An analysis of Kernel Average Misorientation (KAM), as can be seen in Figure 3 (a), confirms that no complete recrystallization phenomenon has taken place upon annealing, as the effect of annealing on the KAM distribution is minimal. Partial recrystallization can be identified as the formation of new strain-free grains in the IPF maps. The KAM parameter measures a pixel-to-pixel misorientation and can be used as a qualitative characterization of the stored energy and dislocation densities [24]. As tungsten recrystallization initiates via a sub-grain coalescence mechanism, this analysis can assist in studying this phenomenon. The observed changes during annealing in our work, i.e. the shortening of the initially elongated grains, point towards the onset of recrystallization. This is confirmed by the slight reduction in LAGB (from $66.23 \%$ to $65.68 \%$ ), which remains close to $66 \%$ for both samples, as can be seen in the Grain Boundary Character Distribution (GBCD) in Figure 3 (b). Correspondingly, a minor increase in Coincidence Site Lattices (CSL) and HAGB fraction was observed after annealing.

The results on the ITER-qualified samples demonstrate that, although recrystallization did not take place, the annealing caused some microstructural changes and while not all information on these changes could be deduced from the IPF maps, the analysis of Pole Figures, KAM and GBCD showed small differences between the microstructure of the ITER specification grade before and after annealing. Future study will help to clarify the effect of annealing temperature on microstructural and textural evolutions in this material.

For the spark plasma sintered samples, Figure 4 shows IPF maps overlapped with Image Quality (IQ) maps.

Apart from a few isolated, unresolved pixels that presented points with Confidence Index lower than 0.1 , several pores are noticed. In the sample SPS2 $\left(1800^{\circ} \mathrm{C}\right.$ and $\left.80 \mathrm{MPa}\right)$ they are 
located preferentially at grain boundaries, while in the samples SPS1 $\left(1700^{\circ} \mathrm{C}\right.$ and $\left.80 \mathrm{MPa}\right)$ and SPS3 $\left(2000^{\circ} \mathrm{C}\right.$ and $\left.70 \mathrm{MPa}\right)$ they are located both between grains and within the grains. The pores are related to incomplete sintering (procedure that still needs to be optimized) [25].

The rapid grain growth during sintering was studied by Ma et al. [26]. Above $1400^{\circ} \mathrm{C}$, the secondary recrystallization temperature, tungsten shows steady grain growth where atomic diffusion is increased and enables a separation between pores and grain boundary. This phenomenon is known as pore-boundary separation. It happens when the grain boundary migration rate is higher than the pore diffusion rate. Pores are separated from the grain boundaries and remain trapped inside the grain. This theory explains the location of pores and is corroborated by the grain growth factor (the ratio between the final and the initial grain size) showed in Table 2. The more the grains grow, the fewer pores remain trapped inside.

For lower growth factors, there are more pores inside the grains. Further studies will be necessary to determine their origin and clarify how they are affected by Spark Plasma Sintering parameters. Considering the analyzed samples, grain growth was observed for all conditions.

When comparing samples SPS1 and SPS2, which were produced using the same pressure (80 $\mathrm{MPa}$ ) it was clear that the higher sintering temperature led to an increased grain growth and, therefore, a larger grain size. The same effect was also observed by Autissier et al. in spark plasma sintered tungsten [27]. Figure 5 (a) shows that the grain size distributions are multimodal for the samples SPS2 and SPS3, as they present multiple non-consecutive peaks. As the sintering temperature increases, the distribution tends to shift to the right due to grain growth, which is a result that could be expected. 
With respect to the misorientation angle distribution, as can be seen in Figure 5 (b), all the spark plasma sintered samples presented a distribution that fits the Mackenzie Distribution, which is a perfectly random distribution and consequently means that they did not develop any preferential crystallographic orientation [28] and, therefore, no significant differences are expected regarding their grain boundary characteristics as well as uniform mechanical response is to be expected.

\section{2-Nano-hardness}

Nano-hardness indentation analysis of the samples was made resulting in the graphs shown in Figure 6. Figure 6 (a) shows the hardness profile as a function of the indenter displacement into surface. The shape of the curves is typical for this type of test. Near the surface, the hardness is larger due to the necessity to create Geometrically Necessary Dislocations (GNDs) in order to accommodate the indenter penetration [29]. At the depth of $1.5 \mu \mathrm{m}$ the bulk hardness was taken as reference value $\left(\mathrm{H}_{0}\right)$, which is then used to normalize the results and construct the Nix-Gao profile [18]. The ITER specification samples exhibit larger values of the bulk hardness compared to the SPS samples. As expected, the annealed IG1300 material showed lower hardness relative to the IG1000 sample, which is an effect of the annealing due to rearrangement of dislocations, confirmed above by the microstructural and EBSD analysis. With respect to the SPS samples, as the sintering temperature increases, a hardness reduction is expected due to grain growth and reduction in the dislocation density. However, as reported by El-Atwani et al. [30] and already observed in Figure 5 (a), a multimodal distribution could lead to greater hardness as well as higher ductility and higher strength. While the smaller grains are responsible for high strength and hardness, larger grains enable ductility and improve toughness[31]. Note that the lower saturated hardness of SPS samples is consistent with the lower yield stress found in tensile tests performed at $400^{\circ} \mathrm{C}$ and 
$600^{\circ} \mathrm{C}$, reported below in in Figure 7. Determination of the tensile mechanical properties at room temperature is impossible as polycrystalline tungsten is fully brittle at this temperature.

Figure 6 (b) shows the hardness-to-reduced modulus ratio, $\mathrm{H} / \mathrm{E}_{\mathrm{r}}{ }^{2}$, which according to Joslin and Oliver[32], characterizes the resistance of material to plastic penetration and is independent on indenter contact area, thus enabling adequate comparison of the results obtained on samples with different mechanical properties.

Considering very small indenter penetration, the hardness-to-modulus ratio represents the resistance of the material to the introduction of GNDs and their propagation towards bulk[33]. As shown in Figure 6 (b), there are no significant differences in the hardness-to-reduced modulus from 10 to $20 \mathrm{~nm}$ of indenter depth, however the resolution of the indentation at such small depths is rather low (i.e. high error bar). At the deeper penetration depth, the ratio $\mathrm{H} / \mathrm{E}_{\mathrm{r}}^{2}$ value appears to be systematically higher for the SPS samples. When the indenter is forced to a distance beyond the initial contact point during the nano-indentation test, the interaction between the indenter and the sample surface is accommodated as both elastic and plastic deformation. Once the force applied to the indenter is relieved, the elastic deformation is removed while the plastic deformation is stored, thereby one can evaluate the energy associated with the stored deformation [32]. This storage is accommodated by the formation of GNDs, as shown in detail by Nix and Gao [29]. As the indenter is forced into the sample surface, GNDs are required to account for the permanent shape change in the surface region. As pointed out by the equation $\mathrm{H} / \mathrm{E}_{\mathrm{r}}^{2}$, for a given hardness, the lower the reduced-modulus, the larger the elastic deformation and the smaller the irreversible deformation. On the other hand, for a given reduced-modulus, the larger the hardness, the larger will be the hardness-toreduced-modulus ratio. Larger values of $\mathrm{H} / \mathrm{E}_{\mathrm{r}}^{2}$ for the SPS samples, as shown in Figure 6 (b), are related to smaller grain sizes as compared to the dimensions of the elongated grains of 
ITER-specified samples. Smaller grains increase the grain boundary density which hinder and obstruct movement of GNDs propagating away from the penetrating indenter [16]. The obtained results clearly show the trend: the smaller the grain size of SPS samples - the larger their hardness-to-reduced-modulus is. This also reflects the fact that the UFG materials absorb a larger amount of energy upon the penetration of the indenter as compared to the ITER specification grade.

\section{3-Tensile Test}

In the frame of this work, IG1000 and SPS3 samples were also tested to investigate the tensile properties at elevated temperature, namely at $400^{\circ} \mathrm{C}$ and $600^{\circ} \mathrm{C}$. For the IG1000, the tensile tests were performed on specimens with grains oriented parallel (longitudinal) and perpendicular (transversal) to the loading direction. SPS3 does not have any microstructural anisotropy and therefore the samples were cut arbitrarily. The tests were performed with a deformation speed of $0.2 \mathrm{~mm} \mathrm{~min}^{-1}$ (corresponding to strain rate $10^{-4} \mathrm{~s}^{-1}$ ). The engineering stress-strains curves are shown in Figure 7.

The presented stress-strain curves show clearly the impact of the microstructure on the onset of ductility and uniform elongation of the material. The IG1000 sample loaded in the transversal direction (i.e. IG1000-T) appears to be brittle at $400^{\circ} \mathrm{C}$ and it breaks in the linear elastic regime upon a load of $450 \mathrm{MPa}$. The IG1000 sample tested in the longitudinal direction (IG1000-L) is ductile at $400^{\circ} \mathrm{C}$, but the uniform elongation is essentially limited to $12 \%$. The uniform elongation of the SPS3 is twice as high at $400^{\circ} \mathrm{C}$, and it even increases at $600^{\circ} \mathrm{C}$. Whereas, both configurations of the IG1000 product show the uniform elongation of about $2-3 \%$ only being tested at $600^{\circ} \mathrm{C}$. The early necking deformation therefore occurs resulting in the low uniform elongation. Note that the obtained here data are fully compatible with the results presented for IG1000 (but tested at $300^{\circ} \mathrm{C}$ and $500^{\circ} \mathrm{C}$ ) in Wirtz et al. [34]. 
These pronounced differences in the uniform elongation of SPS and ITER specification material could be related to the reduced dislocation density (due to high temperature sintering of SPS materials), while differences in grain boundary morphology should also have an impact on the results. The present results indicate that the ultra-fine grain size can indeed improve such important mechanical property as the uniform elongation.

\section{4-Conclusions}

EBSD characterization, nano-indentation and tensile testing were performed to analyze properties of $\mathrm{W}$ products obtained by different routes. Namely, the double hammered ITER specification grade and Spark Plasma Sintered samples were studied.

The EBSD analysis for the ITER specification tungsten showed slight changes in texture and microstructure upon annealing up to $1300^{\circ} \mathrm{C}$. The $\mathrm{KAM}$ distribution revealed a small reduction in the energy stored after annealing, although no significant recrystallization occurred. Further studies, involving higher annealing temperatures, will be carried out to clarify the effect of annealing on the microstructure and texture.

With respect to the Spark Plasma Sintered samples, texture-free samples were produced and the following behavior was observed for all sintered conditions: grain growth, pores within and between grains and pore-boundary separation phenomena. A multi-modal grain size distribution was observed in the SPS2 and SPS3 samples.

The nano-indentation analysis, done at room temperature, showed that ITER specification material has a higher bulk hardness as compared to the SPS samples, which could be related to the observed multi-modal grain size distribution. However, the amount of energy stored for 
the plastic deformation upon indentation was pronouncedly higher in the case of SPS materials, which indicates the high capacity of this material to accommodate plastic deformation.

Tensile tests revealed higher yield stress for IG1000 in all tested temperatures (in line with higher bulk hardness) and brittle behavior of the transversal sample at $400^{\circ} \mathrm{C}$. Spark Plasma Sintering of UFG tungsten proved to produce samples with increased uniform elongation, but the yield stress is lower than that of the ITER specification material.

\section{Acknowledgement}

This work has been carried out within the framework of Erasmus Mundus International Doctoral College in Fusion Science and Engineering (Fusion-DC). Support from Czech Science Foundation through grant no. 17-23154 is also acknowledged. The work was also partially supported by the funding received from the Euratom research and training programme 2014-2018 under grant agreement No 633053 (EUROfusion/Enabling Research

programme). The views and opinions expressed herein do not necessarily reflect those of the European Commission or of the ITER Organization. 


\section{References}

[1] T. Hirai, F. Escourbiac, V. Barabash, A. Durocher, A. Fedosov, L. Ferrand, T. Jokinen, V. Komarov, M. Merola, S. Carpentier-Chouchana, N. Arkhipov, V. Kuznetcov, A. Volodin, S. Suzuki, K. Ezato, Y. Seki, B. Riccardi, M. Bednarek, P. Gavila, Status of technology R\&D for the ITER tungsten divertor monoblock, J. Nucl. Mater. 463 (2015) 1248-1251. doi:10.1016/j.jnucmat.2014.12.027.

[2] T. Hirai, S. Panayotis, V. Barabash, C. Amzallag, F. Escourbiac, A. Durocher, M. Merola, J. Linke, T. Loewenhoff, G. Pintsuk, M. Wirtz, I. Uytdenhouwen, Use of tungsten material for the ITER divertor, Nucl. Mater. Energy. 0 (2016) 1-7. doi:10.1016/j.nme.2016.07.003.

[3] M. Rieth, S.L. Dudarev, S.M. Gonzalez De Vicente, J. Aktaa, T. Ahlgren, S. Antusch, D.E.J. Armstrong, M. Balden, N. Baluc, M.F. Barthe, W.W. Basuki, M. Battabyal, C.S. Becquart, D. Blagoeva, H. Boldyryeva, J. Brinkmann, M. Celino, L. Ciupinski, J.B. Correia, A. De Backer, C. Domain, E. Gaganidze, C. Garcia-Rosales, J. Gibson, M.R. Gilbert, S. Giusepponi, B. Gludovatz, H. Greuner, K. Heinola, T. Hoschen, A. Hoffmann, N. Holstein, F. Koch, W. Krauss, H. Li, S. Lindig, J. Linke, C. Linsmeier, P. Lopez-Ruiz, H. Maier, J. Matejicek, T.P. Mishra, M. Muhammed, A. Munoz, M. Muzyk, K. Nordlund, D. Nguyen-Manh, J. Opschoor, N. Ordas, T. Palacios, G. Pintsuk, R. Pippan, J. Reiser, J. Riesch, S.G. Roberts, L. Romaner, M. Rosinski, M. Sanchez, W. Schulmeyer, H. Traxler, A. Urena, J.G. Van Der Laan, L. Veleva, S. Wahlberg, M. Walter, T. Weber, T. Weitkamp, S. Wurster, M.A. Yar, J.H. You, A. Zivelonghi, Recent progress in research on tungsten materials for nuclear fusion applications in Europe, J. Nucl. Mater. 432 (2013) 482-500. doi:10.1016/j.jnucmat.2012.08.018.

[4] D. Terentyev, G. De Temmerman, B. Minov, Y. Zayachuk, K. Lambrinou, T.W. Morgan, A. Dubinko, K. Bystrov, G. Van Oost, Synergy of plastic deformation and gas retention in tungsten, Nucl. Fusion. 55 (2015) 1-5. doi:10.1088/0029$5515 / 55 / 1 / 013007$.

[5] G. Lee, J. McKittrick, E. Ivanov, E.A. Olevsky, Densification mechanism and mechanical properties of tungsten powder consolidated by spark plasma sintering, Int. J. Refract. Met. Hard Mater. 61 (2016) 22-29. doi:10.1016/j.ijrmhm.2016.07.023.

[6] Y. Zayachuk, M.H.J. 'T Hoen, P.A. Zeijlmans Van Emmichoven, D. Terentyev, I. Uytdenhouwen, G. Van Oost, Surface modification of tungsten and tungsten-tantalum alloys exposed to high-flux deuterium plasma and its impact on deuterium retention, Nucl. Fusion. 53 (2013) 1-7. doi:10.1088/0029-5515/53/1/013013.

[7] V.I. Dubinko, P. Grigorev, A. Bakaev, D. Terentyev, G. Van Oost, F. Gao, D. Van Neck, E.E. Zhurkin, Dislocation mechanism of deuterium retention in tungsten under plasma implantation, J. Phys. Condens. Matter. 26 (2014) 1-10. doi:10.1088/0953$8984 / 26 / 39 / 395001$.

[8] A. Dubinko, D. Terentyev, A. Bakaeva, M. Hernández-Mayoral, G. De Temmerman, L. Buzi, J.M. Noterdaeme, B. Unterberg, Sub-surface microstructure of single and polycrystalline tungsten after high flux plasma exposure studied by TEM, Appl. Surf. Sci. 393 (2017) 330-339. doi:10.1016/j.apsusc.2016.09.071. 
[9] D. Terentyev, X. Xiao, A. Dubinko, A. Bakaeva, H. Duan, Dislocation-mediated strain hardening in tungsten: Thermo-mechanical plasticity theory and experimental validation, J. Mech. Phys. Solids. 85 (2015) 1-15. doi:10.1016/j.jmps.2015.08.015.

[10] D. Terentyev, V. Dubinko, A. Bakaev, Y. Zayachuk, W. Van Renterghem, P. Grigorev, Dislocations mediate hydrogen retention in tungsten, Nucl. Fusion. 54 (2014) 1-5. doi:10.1088/0029-5515/54/4/042004.

[11] D. Terentyev, G. De Temmerman, T.W. Morgan, Y. Zayachuk, K. Lambrinou, B. Minov, A. Dubinko, K. Bystrov, G. Van Oost, Effect of Damaging Temperature on Deuterium Retention in Tungsten, J. Appl. Phys. 117, 8330 (2015) 1-10. http://adsabs.harvard.edu/abs/2015APS..DPPJM1004S.

[12] N. Castin, A. Bakaev, G. Bonny, A.E. Sand, L. Malerba, D. Terentyev, On the onset of void swelling in pure tungsten under neutron irradiation: An object kinetic Monte Carlo approach, J. Nucl. Mater. 493 (2017) 280-293. doi:10.1016/j.jnucmat.2017.06.008.

[13] Y. Zayachuk, I. Tanyeli, S. Van Boxel, K. Bystrov, T.W. Morgan, S.G. Roberts, Combined effects of crystallography, heat treatment and surface polishing on blistering in tungsten exposed to high-flux deuterium plasma, Nucl. Fusion. 56 (2016) 86007. doi:10.1088/0029-5515/56/8/086007.

[14] A. Dubinko, D. Terentyev, A. Bakaeva, K. Verbeken, M. Wirtz, M. HernándezMayoral, Evolution of plastic deformation in heavily deformed and recrystallized tungsten of ITER specification studied by TEM, Int. J. Refract. Met. Hard Mater. 66 (2017) 105-115. doi:10.1016/j.ijrmhm.2017.03.004.

[15] A. Dubinko, D. Terentyev, A. Bakaeva, T. Pardoen, M. Zibrov, T.W. Morgan, Effect of high flux plasma exposure on the micro-structural and -mechanical properties of ITER specification tungsten, Nucl. Instruments Methods Phys. Res. Sect. B Beam Interact. with Mater. Atoms. 393 (2017) 155-159. doi:10.1016/j.nimb.2016.10.041.

[16] F.J. Humphreys, M. Hatherly, Recrystallization and Related Annealing Phenomena: Second Edition, 2004. doi:10.1016/B978-0-08-044164-1.X5000-2.

[17] F.-Z. Xia, H.-G. Wei, M.-P. Wang, D.-H. Zhu, Investigation of normal recrystallization and abnormal recrystallization in pure tungsten sheet by EBSD, Rmhm. 52 (2015) 98103. doi:10.1016/j.ijrmhm.2015.05.009.

[18] J. Reiser, M. Rieth, B. Dafferner, A. Hoffmann, X. Yi, D.E.J. Armstrong, Tungsten foil laminate for structural divertor applications - Analyses and characterization of tungsten foil, J. Nucl. Mater. 424 (2012) 197-2013. doi:10.1016/j.jnucmat.2013.01.295.

[19] E. Gomes, K. Verbeken, J. Gautam, L. Kestens, Evolution of the microstructural surface characteristics during annealing, Mater. Sci. Eng. A. 561 (2013) 312-316. doi:10.1016/j.msea.2012.09.073.

[20] Y.Z. Jia, W. Liu, B. Xu, G.N. Luo, S.L. Qu, T.W. Morgan, G. De Temmerman, Mechanism for orientation dependence of blisters on W surface exposed to D plasma at low temperature, J. Nucl. Mater. 477 (2016) 165-171. doi:10.1016/j.jnucmat.2016.05.011. 
[21] H.Y. Xu, Y.B. Zhang, Y. Yuan, B.Q. Fu, A. Godfrey, G. De Temmerman, W. Liu, X. Huang, Observations of orientation dependence of surface morphology in tungsten implanted by low energy and high flux D plasma, J. Nucl. Mater. 443 (2013) 452-457. doi:10.1016/j.jnucmat.2013.07.062.

[22] D.F. Johnson, E. a. Carter, Hydrogen in tungsten: Absorption, diffusion, vacancy trapping, and decohesion, J. Mater. Res. 25 (2010) 315-327. doi:10.1557/JMR.2010.0036.

[23] P. Grigorev, D. Terentyev, V. Dubinko, G. Bonny, G. Van Oost, J.M. Noterdaeme, E.E. Zhurkin, Nucleation and growth of hydrogen bubbles on dislocations in tungsten under high flux low energy plasma exposure, Nucl. Instruments Methods Phys. Res. Sect. B Beam Interact. with Mater. Atoms. 352 (2015) 96-99. doi:10.1016/j.nimb.2014.11.103.

[24] S.I. Wright, M.M. Nowell, D.P. Field, Fiel, A Review of Strain Analysis Using Electron Backscatter Diffraction, Microsc. Microanal. 17 (2011) 316-329. doi:10.1017/S1431927611000055.

[25] K. Arshad, J. Wang, Y. Yuan, Y. Zhang, Z.J. Zhou, G.H. Lu, Development of tungsten-based materials by different sintering techniques, Int. J. Refract. Met. Hard Mater. 50 (2015) 253-257. doi:10.1016/j.ijrmhm.2015.02.004.

[26] J. Ma, J. Zhang, W. Liu, Z. Shen, Suppressing pore-boundary separation during spark plasma sintering of tungsten, J. Nucl. Mater. 438 (2013) 199-203. doi:10.1016/j.jnucmat.2013.03.042.

[27] E. Autissier, M. Richou, L. Minier, F. Naimi, G. Pintsuk, F. Bernard, Spark plasma sintering of pure and doped tungsten as plasma facing material, Phys. Scr. T159 (2014) 14034. doi:10.1088/0031-8949/2014/T159/014034.

[28] O. Engler, V. Randle, Introduction to Texture Analysis: Macrotexture, Microtexture and Orientation Mapping, 2nd ed., CRC Press Taylor \& Francis Group, 2010. doi:interface shear stre.

[29] W.D. Nix, H.J. Gao, Indentation size effects in crystalline materials: A law for strain gradient plasticity, J. Mech. Phys. Solids. 46 (1998) 411-425. doi:10.1016/s00225096(97)00086-0.

[30] O. El-Atwani, D. V Quach, M. Efe, P.R. Cantwell, B. Heim, B. Schultz, E.A. Stach, J.R. Groza, J.P. Allain, Multimodal grain size distribution and high hardness in fine grained tungsten fabrication by spark plasma sintering, Mater. Sci. Eng. A. 528 (2011) 5670-5677.

[31] Y.M. Wang, E. Ma, Three strategies to achieve uniform tensile deformation in a nanostructured metal, Acta Mater. 52 (2004) 1699-1709. doi:10.1016/j.actamat.2003.12.022.

[32] D.L. Joslin, W.C. Oliver, A new method for analyzing data from continuous depthsensing microindentation tests, J. Mater. Res. 5 (1990) 123-126. doi:10.1557/JMR.1990.0123. 
[33] D. Terentyev, A. Bakaeva, T. Pardoen, A. Favache, E.E. Zhurkin, Surface hardening induced by high flux plasma in tungsten revealed by nano-indentation, J. Nucl. Mater. 476 (2016) 1-4. doi:10.1016/j.jnucmat.2016.04.007.

[34] M. Wirtz, J. Linke, T. Loewenhoff, G. Pintsuk, I. Uytdenhouwen, Thermal shock tests to qualify different tungsten grades as plasma facing material, Phys. Scr. T167 (2016) 14015. doi:10.1088/0031-8949/T167/1/014015. 
Table I: Parameters of Spark Plasma Sintered Samples and starting powder characteristics.

\begin{tabular}{|c|c|c|c|c|}
\hline Sample & $\begin{array}{c}\text { Temperature } \\
\left({ }^{\circ} \mathrm{C}\right)\end{array}$ & $\begin{array}{c}\text { Pressure } \\
(\mathrm{MPa})\end{array}$ & $\begin{array}{c}\text { Grain size } \\
(\mu \mathrm{m})\end{array}$ & $\begin{array}{c}\text { Maximal oxygen content } \\
(\%)\end{array}$ \\
\hline SPS1 & 1700 & 80 & $0.4-0.5$ & 0.30 \\
\hline SPS2 & 1800 & 80 & $0.6-0.7$ & 0.20 \\
\hline SPS3 & 2000 & 70 & $1.7-2.1$ & 0.10 \\
\hline
\end{tabular}


Table II: Average initial and final grain size and growth factor of Spark Plasma Sintered Samples.

\begin{tabular}{|l|c|c|c|}
\hline Parameter & SPS1 & SPS2 & SPS3 \\
\hline Initial grain size $(\mu \mathrm{m})$ & $0.4-0.5$ & $0.6-0.7$ & $1.7-2.1$ \\
\hline Final grain size $(\mu \mathrm{m})$ & $1.5-2.3$ & $1.4-5.0$ & $2.7-4.8$ \\
\hline Growth factor & 4 & 5 & 2 \\
\hline
\end{tabular}


Figure 1: Inverse Pole Figure of ITER-qualified samples (a) IG1000 (b) IG1300. BA bar axis; ND normal direction. Color code with respect to BA. Black lines represent High-Angle Grain Boundaries $\left(>15^{\circ}\right)$ and white lines represent Low-Angle Grain Boundaries $\left(<15^{\circ}\right)$.

Figure 2: Pole Figures of ITER-qualified samples. (a) IG1000 and (b) annealed IG1300. Levels: $1.5,2.0,2.5,3.0$ and 3.5.

Figure 3: (a) Kernel Average Misorientation (KAM) distribution and (b) Grain Boundary Character Distribution (GBCD) of ITER-qualified samples.

Figure 4: IPF maps overlapped with IQ maps of Spark Plasma Sintered samples, (a) SPS1, (b) SPS2, and (c) SPS3. Color code with respect to axial direction.

Figure 5: (a) Grain size distribution and (b) misorientation angle distribution of Spark Plasma Sintered samples.

Figure 6: (a) Hardness and (b) hardness-to-reduced modulus ratio as a function of indenter penetration for all samples.

Figure 7: Engineering stress - engineering strain relationship of the IG1000 and SPS3 tungsten tested at (a) $400^{\circ} \mathrm{C}$ and (b) $600^{\circ} \mathrm{C}$, at $0.2 \mathrm{~mm} / \mathrm{min}$ cross-head speed. 

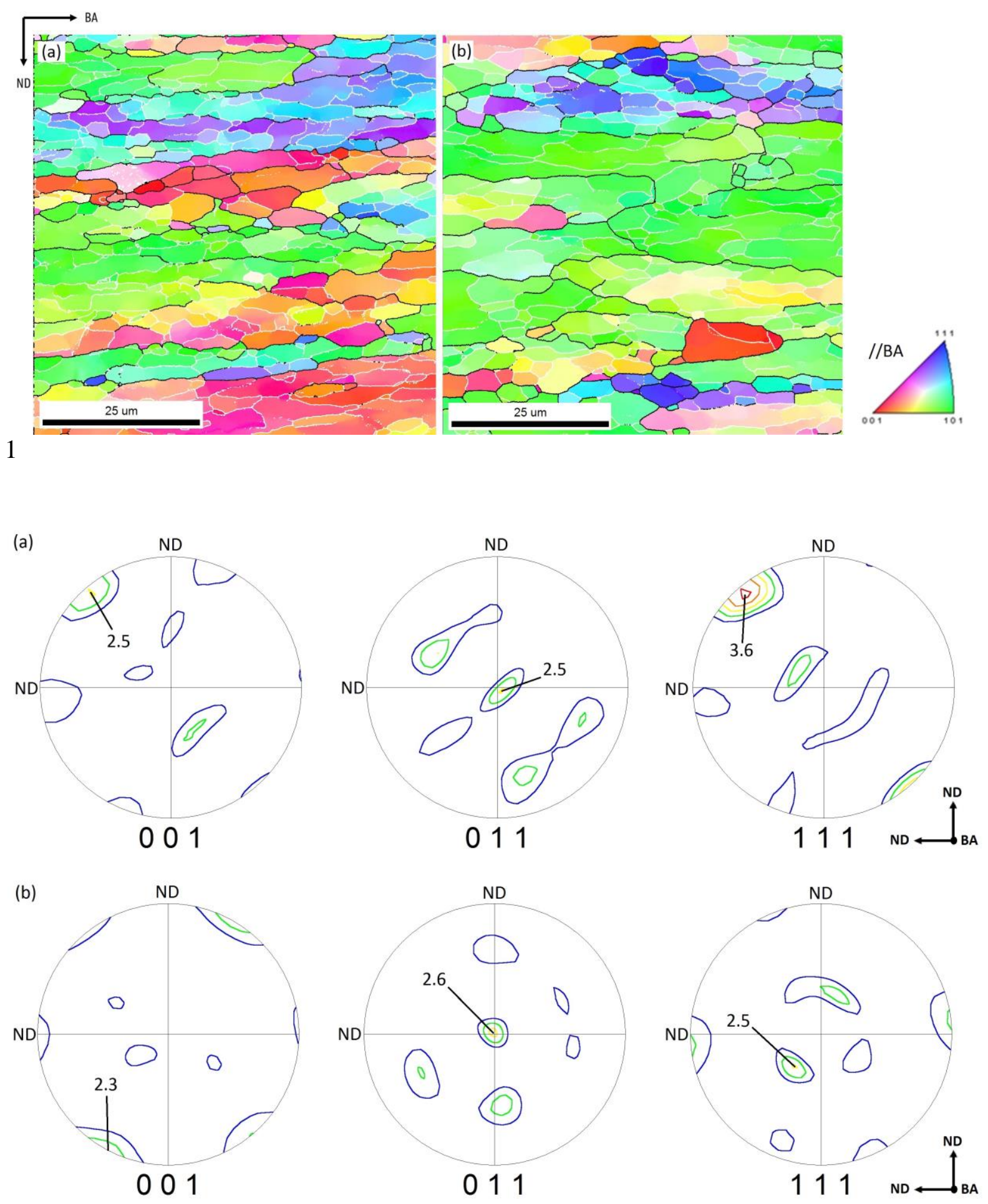

2 
(a) KAM - Kernel Average Misorientation

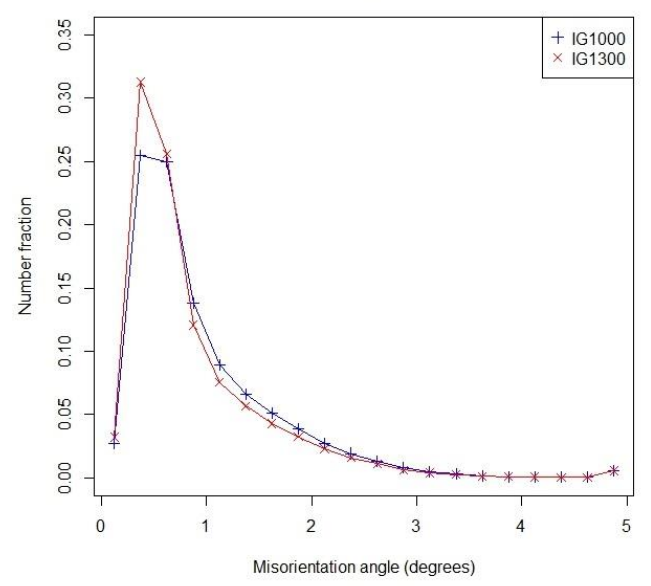

(b) GBCD - Grain Boundary Character Distribution

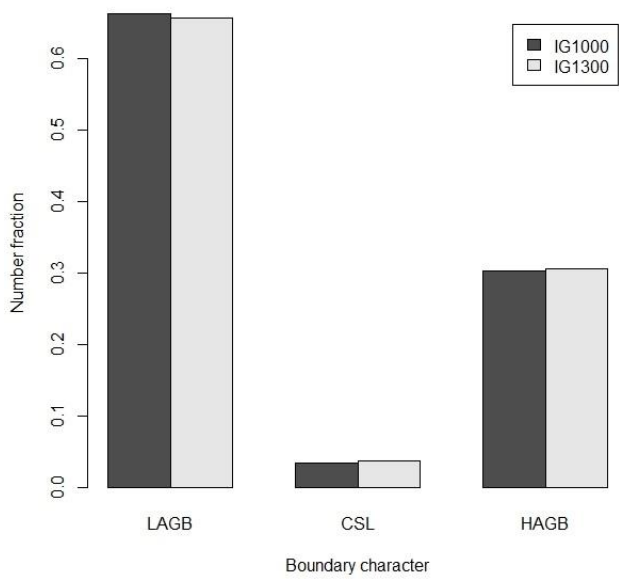

3

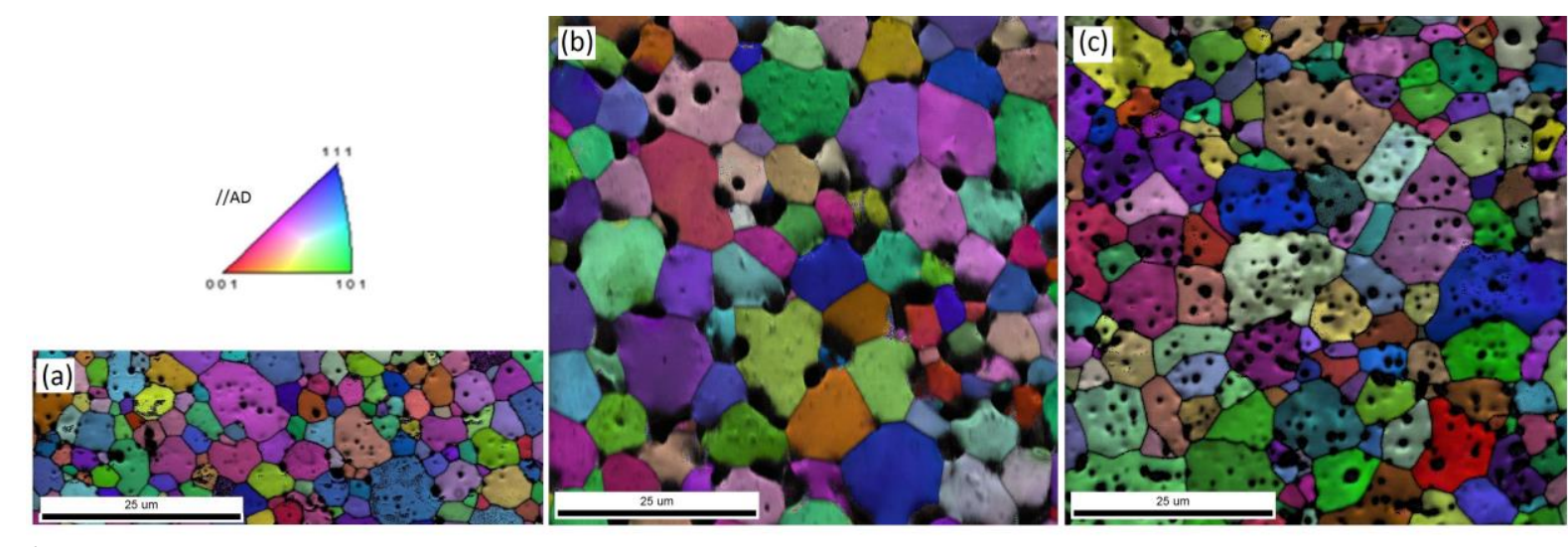

4 
(a)

Grain Size Distribution

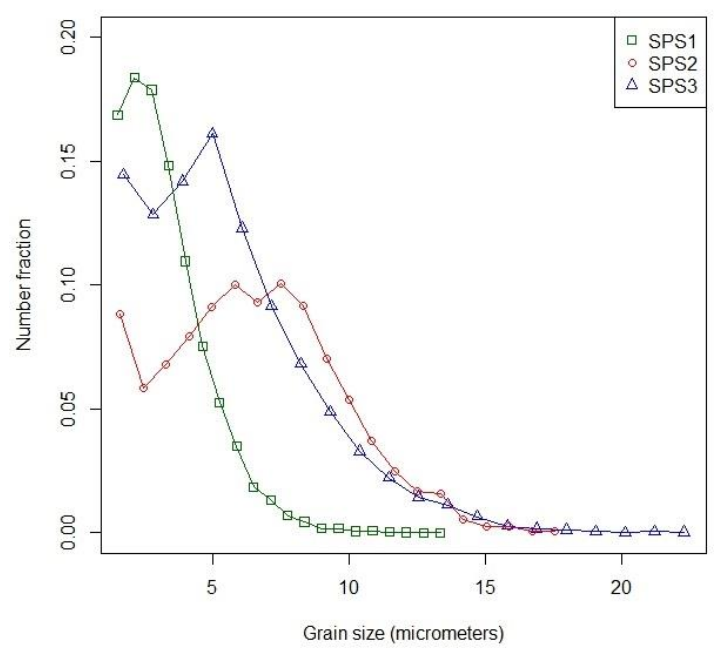

(b) Misorientation Angles Distribution

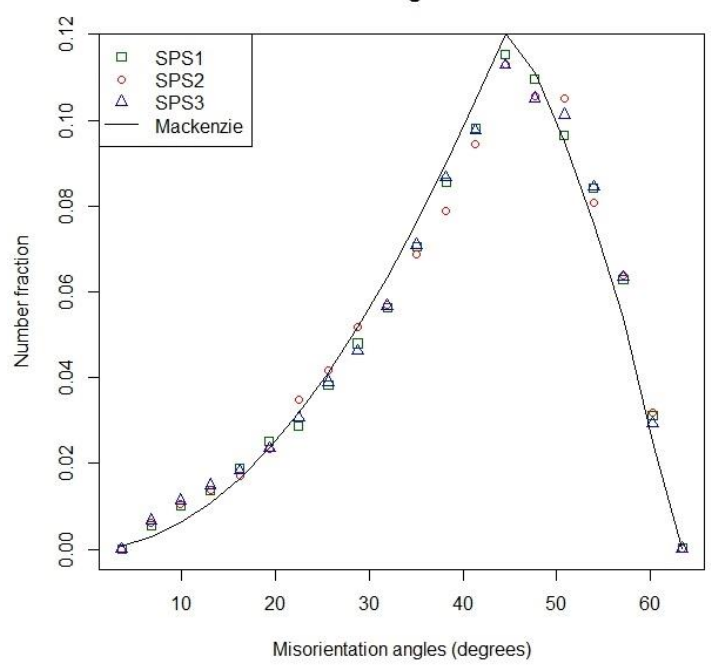

5

(a)

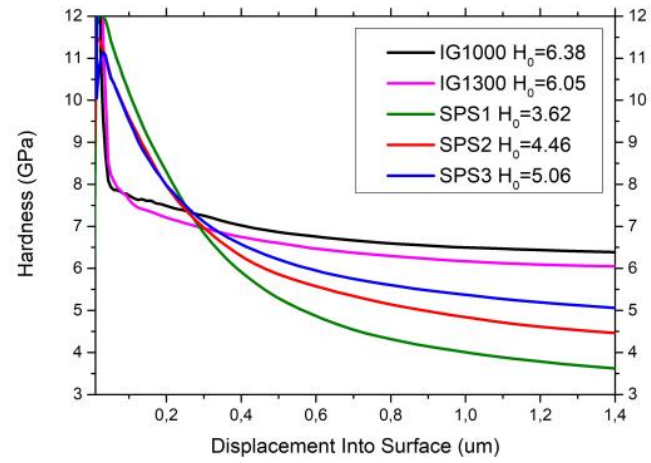




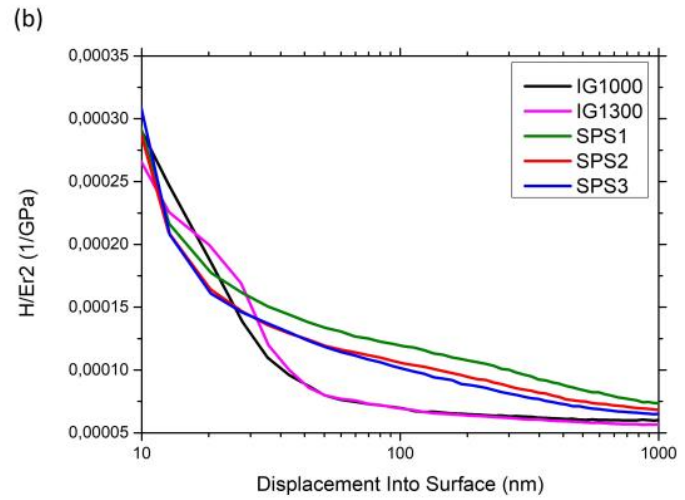

6

(a)
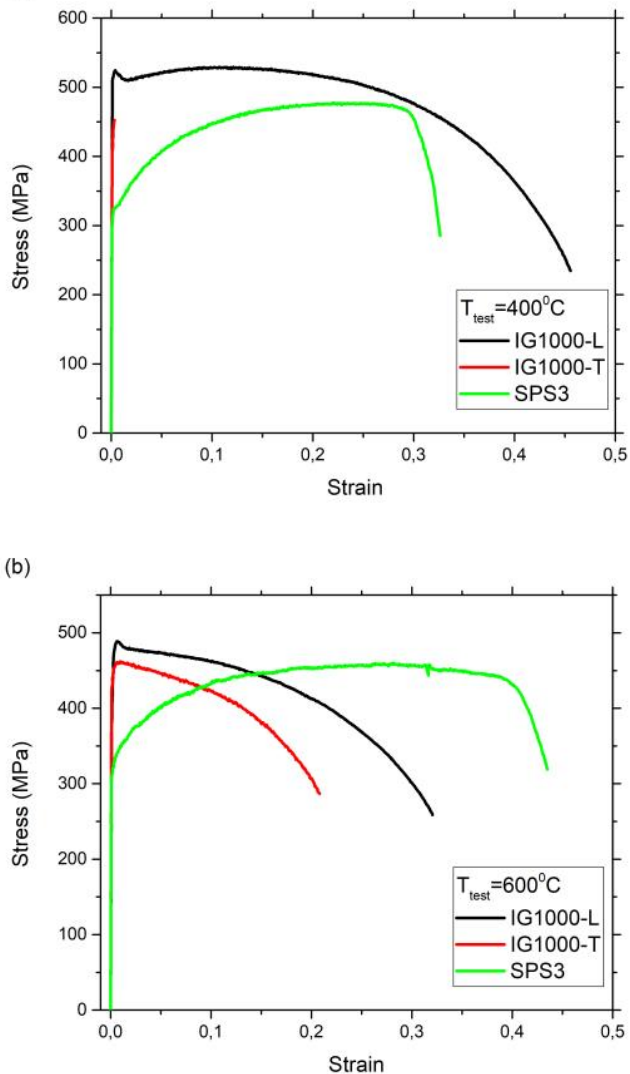

7 